\title{
Evaluasi kesesuaian jenis dan penataan tanaman pada lansekap jalan di Jalan Dharma Giri Gianyar
}

\author{
Ida Bagus Putu Krisnayana ${ }^{1}$, Ni Wayan Febriana Utami ${ }^{1 *}$, Ida Ayu Mayun ${ }^{2}$ \\ 1. Prodi Arsitektur Pertamanan, Fakultas Pertanian, Universitas Udayana, JL. PB Sudirman, \\ Denpasar, Indonesia \\ 2. Program Studi Agroekoteknologi, Fakultas Pertanian, Universitas Udayana, JL. PB Sudirman, \\ Denpasar, Indonesia \\ *E-mail: wayan_febriana@unud.ac.id
}

\begin{abstract}
Evaluation of plant suitability and arrangement on Dharma Giri streetscape in Gianyar. Street infrastructure is now equipped with various kinds of plant elements that known as streetscape, so the existence of the street is not monotonous. Beside the landscape of the street also has a function as a medium for green open space. Therefore, the selection of plant species and arrangement of plants in streetscape must be in accordance with the criteria of plant morphology of the streetscape. Evaluation was carried out based on the problems that occur in the suitability of species and arrangement of plants in the landscape of the street. The purpose of this study was to determine the existing conditions found on the streetscape on the Dharma Giri and to determine the suitability of species and arrangement of plants as a streetscape plant. The method used in this research was field survey with a qualitative approach. The results showed that the general condition of the vegetation and plant selection in Dharma Giri streetscape was almost in accordance with the growing conditions needed by the plants. It conditions generally grow well. Mostly the plants were planted in the median part of the street and also in both side of the street which was also able to adapt with direct sunlight exposure and was not require high intensity of watering. It was also observed from the aspect of arrangement using the approach of the three principles of design which includes themes, rhythm, and balance. However, the plant maintenance activities needs to be improved so it possibly maintained the esthetics and function of the streetscape.
\end{abstract}

Keywords: design principle, landscape plants, plant ecology, road infrastructure

\section{Pendahuluan}

Keberadaan lansekap jalan menjadi sangat penting sebagai infrastruktur jalan untuk keselamatan pengguna jalan. Berdasarkan Tata Cara Teknik Pelaksanaan Lansekap menyebutkan bahwa lansekap jalan merupakan wajah dari karakter lahan yang terbentuk pada lingkungan jalan baik yang terbentuk dari elemen lansekap alamiah maupun elemen lansekap buatan manusia yang disesuaikan dengan kondisi lingkungan dan juga di sesuaikan dengan persyaratan geometrik jalan. Lansekap jalan dapat berupa median jalan, bahu jalan dan trotoar. Median jalan merupakan salah satu kelengkapan badan jalan yang sangat penting karena berfungsi untuk memisahkan arus lalu-lintas yang berlawanan arah,sebagai infrastruktur jalan serta pelengkap elemen lanskap jalan yang dapat meningkatkan keamanan dan kelancaran lalu-lintas. Oleh karena itu pemilihan jenis dan penataan tanaman pada lansekap jalan harus sesuai dengan kriteria morfologi tanaman lanskap jalan dan penataannya pada lansekap jalan. Evaluasi dilakukan berdasarkan permasalahanpermasalahan yang terkait dengan kesesuaian jenis dan penataan tanaman pada lansekap jalan, antara lain mengenai penataan dan pemilihan tanaman lansekap jalan yang belum memenuhi regulasi yang ada. Permasalahan yang ditemui yaitu mengenai peletakan dan pemilihan beberapa tanaman pada lokasi penelitian yang belum sesuai dengan Permen PU No 5 Tahun 2012 Tentang Pedoman Penanaman Pohon Pada Sistem Jaringan Jalan. Maka dari itu tujuan dilakukannya penelitian ini adalah untuk dapat mengetahui kondisi pada tapak penelitian serta kesesuaian dan penataan vegetasi pada lansekap jalan di Jalan Dharma Giri Gianyar. 


\section{Metode Penelitian}

\subsection{Waktu dan Lokasi Penelitian}

Penelitian dilakukan dari bulan Juni 2018 sampai dengan bulan Oktober 2018. Lokasi penelitian terletak di Jalan Dharma Giri, Kecamatan Gianyar, Kabupaten Gianyar, Bali (Gambar 1).

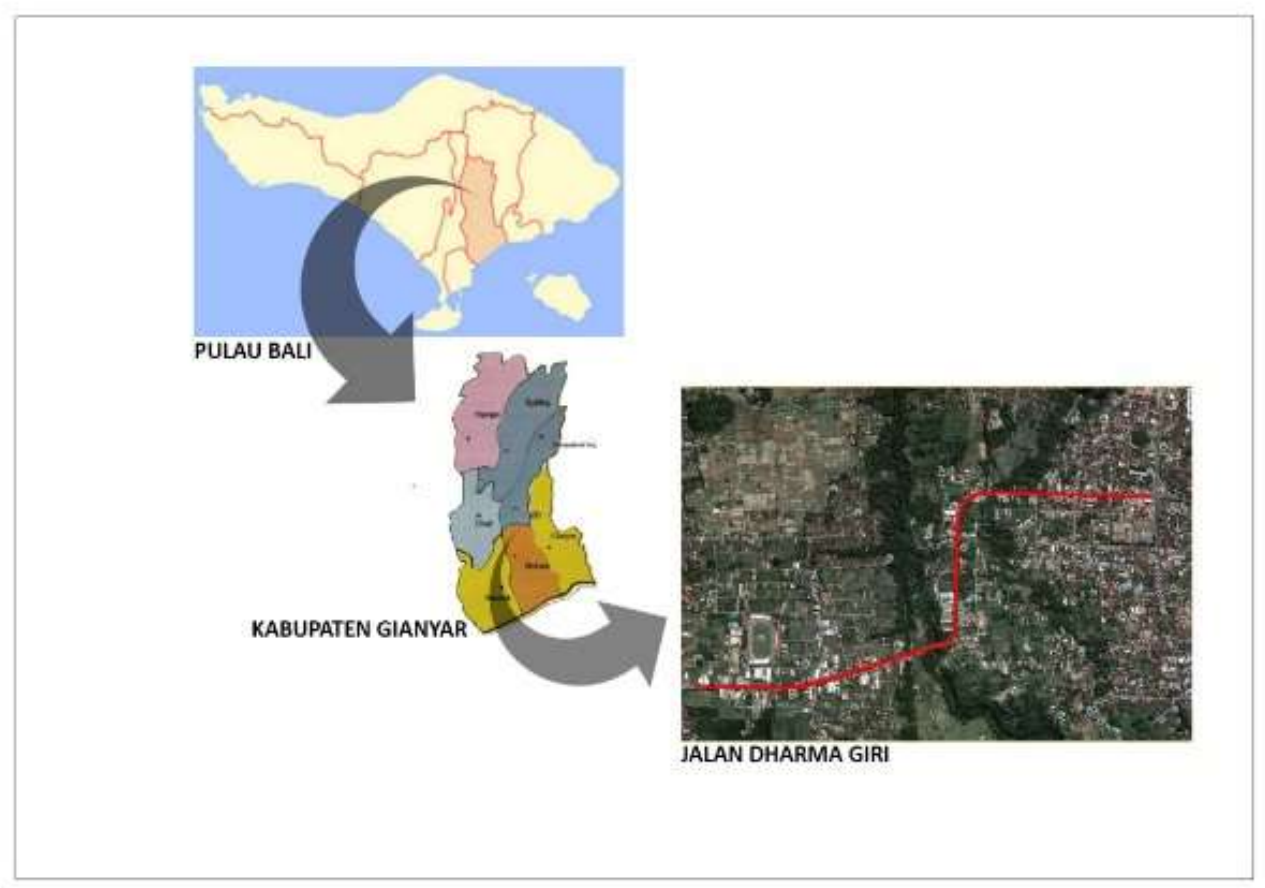

Gambar 1. Peta Lokasi Penelitian

\subsection{Alat dan Bahan}

Alat dan bahan yang digunakan dalam penelitian ini antara lain peta dasar kawasan penelitian, lembar wawancara beserta kamera digital, alat tulis dan komputer dengan piranti lunak Microsoft Office, Google Earth, Auto CAD, Adobe Photoshop.

\subsection{Metode Penelitian}

Metode yang digunakan dalam penelitian ini adalah metode surveiy dengan pendekatan kuantitatif. Metode surveiy dilakukan dengan mengecek langsung di lapangan untuk mengetahui kondisi eksisting lansekap jalan yang kemudian dianalisis dengan menghitung jumlah serta kesesuaian jenis vegetasi pada lokasi penelitian. Metode penelitian ini menggunakan beberapa teknik pengumpulan data, yaitu:

\subsubsection{Observasi}

Observasi yang dilakukan dilapangan dengan cara melakukan pengamatan langsung di Jalan Dharma Giri Gianyar. Hal yang diperhatikan dalam pengumpulan data lapangan yaitu berupa pengamatan terhadap kondisi biofisik yang meliputi topografi, keadaan tanah, serta keragaman vegetasi.

\subsubsection{Wawancara}

Wawancara ditujukan kepada instansi berwenang dalam hal ini merupakan Pemerintah Daerah Kabupaten Gianyar di Dinas Pekerjaan Umum dan Penataan Ruang Bidang Pertamanan yang memahami dan mengetahui kondisi di jalan Dharma Giri. Topik yang diangkat dalam wawancara berupa dasar pemilihan beserta penataan tanaman pada Jalan Dharma Giri Gianyar.

\subsubsection{Studi Pustaka}

Literatur yang digunakan dalam penelitian ini yaitu mengenai topografi, iklim, data kelas jalan, dan pedoman penanaman pohon pada sistem jaringan jalan rangkuman semua data yang diperlukan terdapat pada Tabel 1. 
Tabel 1. Bentuk, Jenis dan Sumber Studi Pustaka

\begin{tabular}{|c|c|c|c|c|}
\hline No & Data & $\begin{array}{c}\text { Jenis Data } \\
\text { Primer/Sekunder }\end{array}$ & Sumber Data & Analisis Data \\
\hline 1 & $\begin{array}{l}\text { Peta Dasar } \\
\text { Lokasi } \\
\text { Penelitian }\end{array}$ & $\begin{array}{c}\text { Primer dan } \\
\text { Sekunder }\end{array}$ & $\begin{array}{c}\text { Observasi, } \\
\text { Dinas PU } \\
\text { Kabupaten } \\
\text { Gianyar }\end{array}$ & $\begin{array}{c}\text { Spasial dan } \\
\text { Deskriptif }\end{array}$ \\
\hline 2 & Iklim & Sekunder & BMKG & $\begin{array}{c}\text { Deskriptif dan } \\
\text { Tabulasi }\end{array}$ \\
\hline 3 & $\begin{array}{c}\text { Daftar Jaringan } \\
\text { Jalan }\end{array}$ & Sekunder & $\begin{array}{c}\text { Dinas PU } \\
\text { Kabupaten } \\
\text { Gianyar }\end{array}$ & Deskriptif \\
\hline 4 & Kondisi Tanah & Sekunder & $\begin{array}{c}\text { Dinas PU } \\
\text { Kabupaten } \\
\text { Gianyar }\end{array}$ & Deskriptif \\
\hline 5 & $\begin{array}{c}\text { Keragaman } \\
\text { Vegetasi }\end{array}$ & Primer & Observasi & $\begin{array}{l}\text { Deskriptif dan } \\
\text { Tabulasi }\end{array}$ \\
\hline 6 & Wawancara & Primer & $\begin{array}{c}\text { Dinas PU } \\
\text { Kabupaten } \\
\text { Gianyar }\end{array}$ & Deskriptif \\
\hline
\end{tabular}

\subsection{Metode Analisis Data}

Metode analisis yang digunakan untuk mengolah data yang dikumpulkan antara lain analisis secara deskriptif dan juga analisis vegetasi, berikut merupakan penjelasan dari masing masing metode:

\subsubsection{Analisis Deskriptif}

Dalam penelitian ini, analisis deskriptif diterapkan dalam penjabaran hasil dari kesesuaian skoring yang mana hasilnya akan menunjukan tanaman yang terdapat pada lansekap jalan memiliki fungsi yang sesuai dengan aspek ekologi, arsitektural serta estetika dan juga menjelaskan mengenai penataan tanaman yang diterapkan pada lokasi penelitian.

\subsubsection{Analisis Vegetasi}

Pengumpulan data keragaman vegetasi akan dilakukan dengan menginventarisasi vegetasi yang berada pada sepanjang Jalan Dharma Giri yang dibagi menjadi tiga segmen jalan yang berbeda. Analisis vegetasi dilakukan dengan cara melihat secara visual pada lokasi penelitian dan mencatat ragam vegetasi yang berada pada tapak penelitian, mengambil gambar lalu mencari informasi tentang tanaman tersebut dengan bantuan pustaka sekunder atau bertanya pada orang yang tahu mengenai jenis tumbuhan tersebut. Setelah terkumpul lalu dikelompokan berdasarkan strata pohon, semak atau perdu, dan penutup tanah. Data yang telah dikelompokan sesuai kriteria akan dinilai dan ditabulasikan berdasarkan tiga aspek yaitu aspek ekologis, aspek arsitektural dan aspek estetika.

Nilai kesesuaian komponen akan di tentukan berdasarkan kriteria penilaian. Kriteria penilaian dinilai berdasarkan tiga aspek dengan besar bobot 20 untuk aspek ekologis, 20 untuk aspek estetika dan 60 untuk aspek arsitektural (saputri, 2017). Penentuan kesesuaian vegetasi dilakukan dengan menjumlahkan seluruh skor tiap jenis vegetasi yang diperoleh dari hasil inventarisasi di lapangan dan akan dilanjutkan dengan mengkalkulasikan penghitungan skor sehingga menghasilkan hasil kesesuaian yang menentukan apakah vegetasi tersebut sesuai atau tidak sesuai. Menurut Agus (2014) skor maksimal tiap vegetasi yang dinilai adalah 100 dan akan dibagi menjadi empat kelas, jika nilai total berjumlah $1-25$ dinyatakan tidak sesuai, jumlah skor 26 - 50 cukup sesuai, jumlah nilai 51 - 75 dinyatakan sesuai dan jumlah nilai 76 - 100 dinyatakan sangat sesuai. 


\subsection{Penentuan Lokasi Penelitian}

Pada lokasi penelitian akan dibagi menjadi 3 segmen jalan yaitu jalan Dharma Giri segmen A, segmen $B$ dan segmen $C$ hal tersebut dilakukan agar dapat mengetahui kondisi eksisting tiap segmen jalan dan untuk mempermudah dalam pengelompokan elemen jalan dan juga inventarisasi vegetasi yang ada di lokasi penelitian, berikut merupakan gambar segmentasi di Jalan Dharma giri (Gambar 2.)

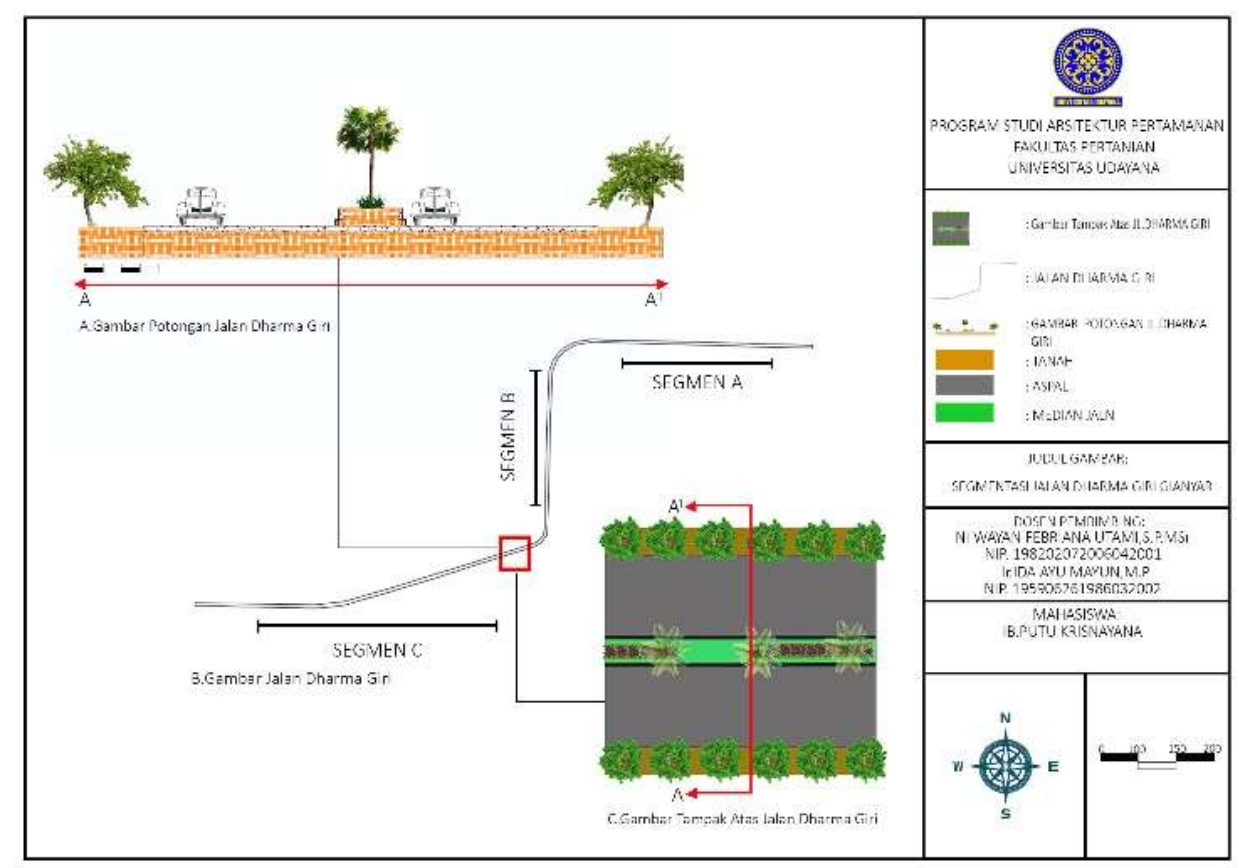

Gambar 2. Segmentasi di Jalan Dharma Giri Gianyar.

\section{Hasil dan Pembahasan}

\subsection{Kondisi Umum Kota Gianyar}

Kecamatan Gianyar merupakan salah satu kecamatan yang ada di Kabupaten Gianyar, Provinsi Bali. Terletak pada ketinggian kurang dari $500 \mathrm{mdpl}$ dan secara geografis terletak antara 8.26'23" - 8.35'01" Lintang selatan dan 115.19'57,9" - 115.22'23,7" Bujur Timur. Suhu maksimum di kecamatan Gianyar mencapai $30^{\circ} \mathrm{C}$ dan suhu minimum mencapai $24^{\circ} \mathrm{C}$ dengan luas wilayah $50,59 \mathrm{~km}^{2}$. Secara administratif Kecamatan Gianyar mempunyai batas-batas wilayah yaitu di bagian utara berbatasan dengan kecamatan Tampaksiring dan Kabupaten Bangli, sebelah timur berbatasan dengan Kabupaten Bangli dan Kabupaten Klungkung, sebelah selatan berbatasan dengan pesisir pantai selat Badung dan sebelah barat berbatasan dengan Kecamatan Blahbatuh. Kawasan ini terdiri dari 17 desa meliputi 8 kawasan perkotaan dan 9 kawasan pedesaan serta 41 desa adat dan 96 banjar.

\subsection{Kondisi Eksisting pada Lansekap Jalan di Jalan Dharma Giri}

\subsubsection{Lokasi dan Kondisi Fisik Jalan}

Tapak Penelitian terletak di Kecamatan Gianyar yaitu di jalan Dharma Giri yang secara administratif terletak diantara perbatasan antara Kecamatan Blahbatuh dan Kecamatan Gianyar. Jalan Dharma Giri melintang dari arah barat Desa Buruan menuju ke arah timur dan berakhir di persimpangan jalan taman Kota Gianyar, jalan ini terletak di kawasan Desa Pekraman Bitera kelurahan Bitera, namun secara administrasi kepemilikan jalan ini merupakan milik Pemerintah Provinsi Bali. Panjang jalan pada tapak penelitian di jalan Dharma Giri adalah sepanjang $3.5 \mathrm{~km}$. Berdasarkan daftar jaringan jalan, Jalan Dharma Giri termasuk dalam kategori jalan arteri sekunder, dengan kriteria memiliki lebar jalan kurang dari $8 \mathrm{~m}$, dengan kecepatan minimal $30 \mathrm{~km} / j a m$ memiliki perlengkapan jalan yang cukup seperti lampu pengaturan lalu lintas, marka jalan, lampu penerangan jalan dan rambu-rambu lalu lintas serta tersedianya jalur khusus bagi sepeda dan dilengkapi dengan median jalan.(Departemen Permukiman dan Prasarana Wilayah tahun 2004). 
Elemen keras yang pada tapak penelitian berjumlah enam jenis yang terletak di jalan Dharma Giri namun di segmen jalan yang berbeda. Elemen tersebut meliputi lampu penerangan jalan yang total dari tiap segmen berjumlah 35 buah, lalu rambu lalu lintas yang meliputi rambu dilarang berhenti, rambu putar balik, rambu wajib kenakan sabuk pengaman, dan rambu dilarang parkir berjumlah 13 buah, lalu median jalan yang terbentang sepanjang jalan Dharma Giri, dan terdapat jalur bagi pengendara roda dua, papan nama yang menunjukan nama jalan dan papan batas wilayah yang masing-masing berjumlah satu buah. Daftar elemen keras pada jalan Dharma Giri dapat dilihat pada Tabel 2.

Tabel 2. Daftar Elemen Keras pada Jalan Dharma Giri

\begin{tabular}{ccccc}
\hline No & Elemen jalan & Segmen Jalan (buah) & C \\
& & B & 14 \\
\hline 1 & Lampu Penerangan Jalan & 12 & 9 & 6 \\
2 & Rambu Lalu Lintas & 6 & 1 & 1 \\
3 & Median Jalan & 1 & 1 & 1 \\
4 & Jalur Pengendara Roda dua & 1 & 1 & 1 \\
5 & Papan Nama Jalan & 1 & - & 1 \\
6 & Papan Batas Wilayah & - & - & 24 \\
\hline
\end{tabular}

Sumber: Observasi, 2018.

Sebagai jalan arteri sekunder, jalan Dharma Giri sudah memenuhi kriteria dengan lebar jalan 6,8 $\mathrm{m}$ pada masing-masing segmen jalannya dan perlengkapan jalan yang memadai. Gambar merupakan Pembagian segmentasi jalan Dharma Giri Segmen A, B dan $C$ dengan tipe jalan empat jalur dua arah dengan median jalan. Segmen A merupakan jalan yang terletak dibagian utara, lalu menuju ke segmen jalan $B$ yang terletak dibagian selatan, dan kearah segmen jalan $\mathrm{C}$ yang terletak dibagian timur.
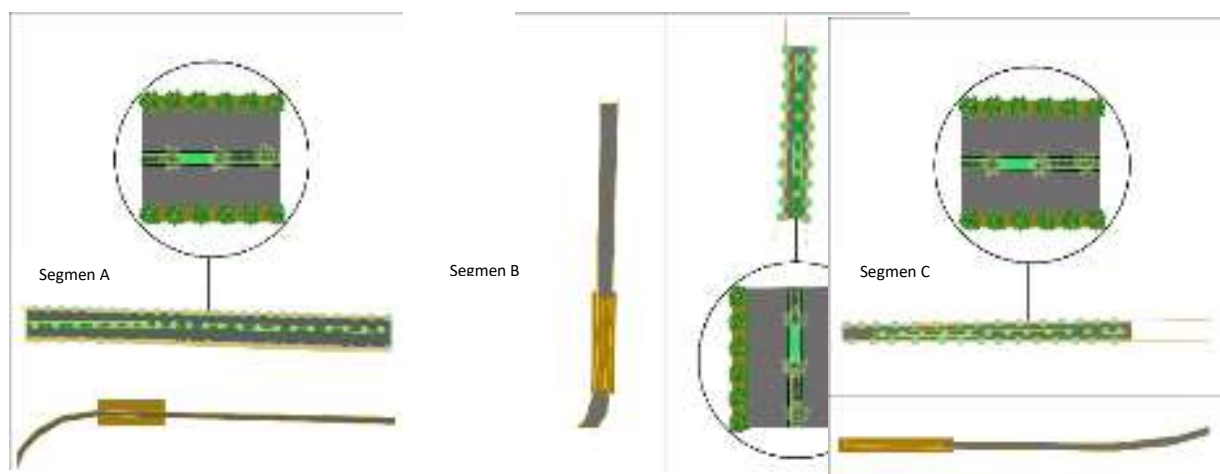

Sumber: Pengolahan Data, 2018.

Gambar 3. Segmentasi Jalan di Jalan Dharma Giri (Segmen A, B, dan C).

\subsubsection{Topografi dan Iklim}

Kondisi topografi di Kecamatan Gianyar khususnya di Jalan Dharma Giri memiliki ketinggian kurang dari 500 meter dari permukaan laut, kondisi Jalan Dharma Giri cenderung datar dan lurus namun sedikit bergelombang. Kondisi iklim diambil dari tahun 2013 sampai 2017 suhu udara rata-rata Kecamatan Gianyar adalah $27,32^{\circ} \mathrm{C}$. Kelembaban udara rata-rata Kecamatan Gianyar adalah $77,6 \%$. Lama penyinaran matahari di Kecamatan Gianyar adalah $65 \%$, dan curah hujan perbulan di Kecamatan Gianyar adalah 166,75 mm.

\subsubsection{Vegetasi}

Berdasarkan hasil inventarisasi pada tapak penelitian terdapat hanya 20 jenis tanaman yang terdiri dari vegetasi penutup tanah, semak atau perdu dan pohon. Vegetasi ini meliputi tanaman yang terdapat di median jalan dan juga bahu jalan dari total vegetasi tanaman penutup tanah hanya terdapat satu jenis, tanaman pohon terdapat lima jenis sedangkan tanaman semak terdapat 13 jenis. Hal terpenting dalam pemilihan tanaman pada lansekap jalan harus memperhatikan fungsinya yaitu sebagai penyerap polutan 
penyerap kebisingan estetika dan sebagai peneduh (Permen PU Nomor 5 tahun 2012 Tentang Pedoman Penanaman Pohon pada Sistem Jaringan Jalan). Pemilihan jenis tanaman pada lokasi penelitian harus didasari oleh fungsi dari vegetasi yang digunakan, fungsi jalan, lingkungan sekitar jalan dan juga syarat penempatannya. Hal ini harus sesuai dengan pemilihan jenis tanaman pada Tata Cara Perencanaan Teknik Lansekap Jalan yang diterbitkan oleh Direktorat Jenderal Bina Marga (1996) dimana berdasarkan lingkungan sekitar jalan dan ketentuan ruang yang tersedia maka pemilihan jenis tanaman perlu memperhatikan fungsi tanaman serta persyaratan penempatannya. Daftar spesies dan strata tanaman yang terdapat pada lansekap jalan di Jalan Dharma Giri dapat dilihat pada Tabel 3.

Tabel 3. Spesies dan Strata Tanaman Pada Lansekap Jalan Dharma Giri

\begin{tabular}{clc}
\hline No & \multicolumn{1}{c}{ Nama } & Strata Tanaman \\
\hline 1 & Kiara Payung (Fillicium decipiens) & Pohon \\
2 & Bungur (L. Speciosa) & Pohon \\
3 & Nusa Indah (Mussaenda phillipica L) & Pohon \\
4 & Kamboja (Plumeria indica) & Pohon \\
5 & Palem Raja (Roystonea regia) & Pohon \\
6 & Kembang Kertas (Bougenvillea) & Semak \\
7 & Puring (Codiaeum variegtum) & Semak \\
8 & Pangkas Merah (Duranta repens) & Semak \\
9 & Pangkas Kuning (Duranta repens) & Semak \\
10 & Bunga Euphorbia (Euphorbia sp.) & Semak \\
11 & Bunga Taiwan Beauty (Euphea hysopifolia) & Semak \\
12 & Bunga Sepatu (Hibiscus rosa-sinensis) & Semak \\
13 & Melati Perancis (Jasminum sambac L) & Semak \\
14 & Jaburan Variegata (Ophiopogon japanicus) & Semak \\
15 & Ararea (Osmoxylon lineare) & Semak \\
16 & Ruelia (Ruellia tuberosa L) & Semak \\
17 & Soka Mini ( Saraca indica) & Semak \\
18 & Pucuk Merah (Syzygium oleana) & Semak \\
19 & Pisang hias (Heliconia densiflora) & Semak \\
20 & Rumput Jepang (Cyperus rotendus) & Penutup Tanah \\
\hline
\end{tabular}

Sumber: Observasi, 2018.

\subsection{Analisis Kesesuaian Vegetasi dan Penataan pada Lansekap Jalan di Jalan Dharma Giri}

\subsubsection{Analisis Kesesuaian Vegetasi}

Menurut Lawalata (2011), tanaman yang ditanam di jalan harus memiliki karakter khusus sesuai dengan kondisi jalan selain memiliki daun atau bunga yang indah. Hal ini disebabkan karena kondisi jalan yang panas karena paparan sinar matahari dan padatnya lalu lintas kendaraan bermotor, berangin dan juga udara telah tercemar asap kotor kendaraan bermotor, tanaman lansekap jalan perlu dipilih secara hati-hati, penataan lansekap memiliki peran yang penting untuk memaksimalkan fungsi kelancaran dan keselamatan jalan. Pemilihan jenis dan penataan tanaman pada lansekap jalan sebaiknya tetap memperhatikan aspek hortikultura dan agronomi yang meliputi ruang dan syarat tumbuh, morfologi, fungsi tanaman dan pemeliharaan.

Kondisi umum vegetasi yang berada pada lansekap jalan di jalan Dharma Giri pada bagian median jalan serta tepi jalan rata-rata pemilihan tanaman sudah hampir sesuai dengan syarat tumbuh yang diperlukan oleh tanaman karena untuk kondisi tanaman secara umum tanaman dapat tumbuh dengan baik. Sebagian besar tanaman yang di tanam pada bagian median jalan dan juga tepi jalan merupakan tanaman yang dapat hidup dengan paparan sinar matahari langsung dan juga penyiraman yang tidak terlalu intensif dalam hal ini hanya perlu penyiraman secukupnya. Terdapat 20 jenis tanaman yang berada di median jalan, tanaman yang lebih mendominasi adalah jenis semak tinggi dan rendah dan hanya terdapat beberapa jenis pohon pada 
median jalan sedangkan pada tepi jalan hanya terdapat satu jenis pohon yang ditanam sepanjang Jalan Dharma Giri.

Median jalan merupakan daerah terbuka tanpa naungan dengan penyiraman tanaman yang dilakukan hanya pada pagi hari. Median jalan yang diamati memiliki lebar total sebesar 3,58 meter, tinggi 0,78 meter, dengan lebar bidang tanam 3,32 meter dan ketinggian tanah dalam median 0,65 meter. Median jalan dengan lebar lebih besar dari 1,5 meter cenderung mudah dalam pemilihan tanamannya, karena tanaman memiliki cukup ruang untuk pertumbuhan tajuknya namun apabila median jalan dengan lebar kurang dari 1,5 meter harus lebih berhati-hati dalam pemilihan tanamannya serta memerlukan perawatan yang lebih intensif dikarenakan lebar dari kanopi tidak boleh melebihi badan jalan. Median jalan pada Jalan Dharma Giri sudah sesuai dari segi media tanam dikarenakan lebar median jalan lebih dari dua meter. Berikut merupakan kondisi pada median jalan pada lokasi penelitian (Gambar.4)

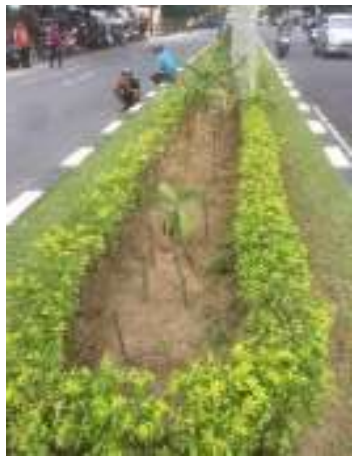

Sumber: Observasi, 2018.
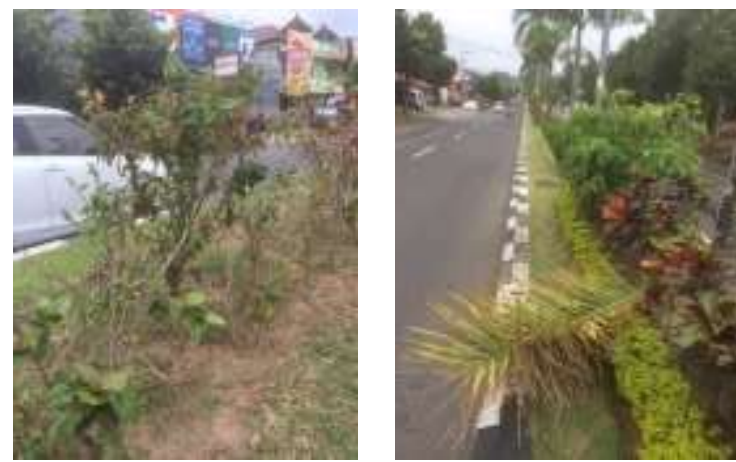

Gambar 4. a) Pisang Hias (Heliconia densiflora), (b) Bunga Sepatu (hibiscus rosa-sinensis), (c) Palem Raja (Roystonea regia) yang Jatuh di Median Jalan.

\subsubsection{Fungsi Tanaman dan Penataan pada Lansekap}

Berdasarkan hasil skoring tanaman yang mendapat predikat kelas kesesuaian sangat sesuai yaitu Nusa Indah, Kembang Kertas, Puring, Pangkas merah dan kuning, Bunga Taiwan Beauty, Bunga Sepatu, Melati Perancis, Jaburan, Ararea, Soka Mini, dan Pucuk Merah. Tanaman dengan predikat sangat sesuai ratarata memenuhi semua kriteria penilaian dengan baik, namun dalam hal ini terdapat beberapa tanaman yang tidak tumbuh dengan baik karena kekeringan yaitu tanaman Bunga Sepatu dan Soka Mini. Apabila dilihat dari segi aspek arsitektural kedua tanaman tersebut memiliki fungsi yang baik sebagai tanaman pengarah, pembatas pandang, penghalang silau, penahan benturan dan pemecah angin karena memiliki karakter tanaman dengan massa daun yang cukup padat dengan jarak tanam yang rapat sehingga dapat memaksimalkan fungsi dari aspek arsitektural. Tanaman dengan predikat kelas kesesuaian sesuai yaitu Kiara Payung, Bungur, Kamboja, Palem Raja, Euphorbia, Ruelia, Pisang Hias dan Rumput Jepang. Beberapa tanaman tersebut diantaranya terdapat tanaman yang tidak tumbuh dengan baik seperti Pisang Hias, Euphorbia dan Bungur yang terlihat kekeringan bahkan sampai dibiarkan mati, lalu kendala lainnya adalah pelepah dari Palem Raja kerap kali jatuh ke badan jalan dan dapat membahayakan pengguna jalan. Pemilihan Euphorbia menjadi sesuatu yang menyalahi Permen PU No 5 Tahun 2012 Tentang Pedoman Penanaman Pohon pada Sistem Jaringan Jalan dikarenakan tumbuhan berduri tidak dibenarkan digunakan sebagai tanaman yang diletakan pada lansekap jalan, untuk hasil skoring vegetasi dapat dilihat pada Tabel 4 .

Tabel 4. Skoring Kesesuaian Vegetasi Pada Lansekap Jalan Dharma Giri

\begin{tabular}{|c|c|c|c|c|c|c|c|c|c|c|}
\hline \multirow[t]{2}{*}{ No } & \multirow[t]{2}{*}{ Nama } & \multicolumn{3}{|c|}{ Letak } & \multicolumn{3}{|c|}{ Skoring } & \multicolumn{3}{|c|}{ Kesesuaian } \\
\hline & & a & $b$ & c & a & b & $\mathrm{c}$ & a & $b$ & C \\
\hline 1 & $\begin{array}{l}\text { Kiara Payung(Fillicium } \\
\text { decipiens) }\end{array}$ & $\checkmark$ & $\checkmark$ & $\checkmark$ & 68 & 68 & 68 & $\mathrm{~s}$ & $\mathrm{~s}$ & $s$ \\
\hline 2 & Bungur (L. Speciosa) & & & $\checkmark$ & & & 76 & & & ss \\
\hline 3 & $\begin{array}{l}\text { Kamboja } \\
\text { (Plumeria indica) }\end{array}$ & $\checkmark$ & $\checkmark$ & $\checkmark$ & 62 & 62 & 62 & $\mathrm{~s}$ & $\mathrm{~s}$ & $\mathrm{~s}$ \\
\hline
\end{tabular}


Lanjutan Tabel 4.

\begin{tabular}{|c|c|c|c|c|c|c|c|c|c|c|}
\hline 4 & $\begin{array}{l}\text { Palem Raja (Roystonea } \\
\text { regia) }\end{array}$ & $\checkmark$ & $\checkmark$ & $\checkmark$ & 54 & 54 & 54 & $\mathrm{~s}$ & $\mathrm{~s}$ & $\mathrm{~s}$ \\
\hline 5 & $\begin{array}{l}\text { Nusa Indah (Mussaenda } \\
\text { phillipica L) }\end{array}$ & & $\checkmark$ & & & 77 & & & ss & \\
\hline 6 & $\begin{array}{l}\text { Kembang Kertas } \\
\text { (Bougenvillea) }\end{array}$ & & & $\checkmark$ & & & 68 & & & $s$ \\
\hline 7 & $\begin{array}{l}\text { Puring (Codiaeum } \\
\text { variegtum) }\end{array}$ & $\checkmark$ & & $\checkmark$ & 67 & & 67 & $s$ & & $s$ \\
\hline 8 & $\begin{array}{l}\text { Pangkas Merah (Duranta } \\
\text { repens) }\end{array}$ & $\checkmark$ & & $\checkmark$ & 75 & & 75 & $\mathrm{~s}$ & & $s$ \\
\hline 9 & $\begin{array}{l}\text { Pangkas kuning (Duranta } \\
\text { repens) }\end{array}$ & & $\checkmark$ & & 75 & 75 & & $\mathrm{~s}$ & $s$ & \\
\hline 10 & Euphorbia (Euphorbia sp) & $\checkmark$ & $\checkmark$ & $\checkmark$ & 53 & 53 & 53 & $\mathrm{~s}$ & $s$ & $s$ \\
\hline 11 & $\begin{array}{l}\text { Bunga Taiwan Beauty } \\
\text { (Euphea hysopifolia) }\end{array}$ & & & $\checkmark$ & 66 & & & & & $\mathrm{~s}$ \\
\hline 12 & $\begin{array}{l}\text { Bunga Sepatu (Hibiscus } \\
\text { rosa-sinensis) }\end{array}$ & $\checkmark$ & & $\checkmark$ & 70 & & 70 & $\mathrm{~s}$ & & $\mathrm{~s}$ \\
\hline 13 & $\begin{array}{l}\text { Melati } \\
\text { Perancis } \\
\text { (Jasminum } \\
\text { sambac L) }\end{array}$ & $\checkmark$ & & $\checkmark$ & 77 & & 77 & SS & & ss \\
\hline 14 & $\begin{array}{l}\text { Jaburan Variegta } \\
\text { (Ophiopogori } \\
\text { japanicus) }\end{array}$ & $\checkmark$ & $\checkmark$ & $\checkmark$ & 70 & 70 & 70 & $\mathrm{~s}$ & $\mathrm{~s}$ & $\mathrm{~s}$ \\
\hline 15 & $\begin{array}{l}\text { Ararea (Osmoxylon } \\
\text { lineare) }\end{array}$ & $\checkmark$ & $\checkmark$ & $\checkmark$ & 78 & 78 & 78 & ss & ss & ss \\
\hline 16 & Ruelia (Ruellia tuberosa) & $\checkmark$ & & $\checkmark$ & 67 & & 67 & $\mathrm{~s}$ & & $s$ \\
\hline 17 & Soka Mini (Saraca indica) & & & $\checkmark$ & & & 77 & & & ss \\
\hline 18 & $\begin{array}{l}\text { Pucuk Merah (Syzygium } \\
\text { oleana) }\end{array}$ & $\checkmark$ & & $\checkmark$ & 80 & & 80 & ss & & ss \\
\hline 19 & $\begin{array}{l}\text { Pisang hias (Heliconia } \\
\text { densiflora) }\end{array}$ & $\checkmark$ & $\checkmark$ & $\checkmark$ & 66 & 66 & 66 & $\mathrm{~s}$ & $\mathrm{~s}$ & $\mathrm{~s}$ \\
\hline 20 & $\begin{array}{l}\text { Rumput Jepang } \\
\text { (Cyperus rotendus) }\end{array}$ & $\checkmark$ & $\checkmark$ & $\checkmark$ & 58 & 58 & 58 & $\mathrm{~s}$ & $\mathrm{~s}$ & $\mathrm{~s}$ \\
\hline
\end{tabular}

Keterangan : $\mathrm{s}=$ sangat sesuai, $\mathrm{s}=$ sesuai

Sumber : : Observasi, 2018.

\subsubsection{Penataan Tanaman Pada Lansekap Jalan}

Dari segi penataan tanaman, penelitian ini menggunakan pendekatan berdasarkan tiga prinsip desain yang meliputi tema, irama, dan keseimbangan. Menurut Budiyono (2012), prinsip desain membantu menentukan bagaimana menggunakan elemen desain, prinsip desain juga dapat membantu dalam membentuk tata letak yang baik. Budiyono juga menambahkan berdasarkan jarak tanaman terhadap perkerasan memiliki kaitan dengan mempertimbangkan pertumbuhan perakaran tanaman agar tidak menganggu struktur perkerasan jalan, sedangkan jarak antar tanaman berpengaruh dalam tema, irama dan keseimbangan. Untuk lansekap Jalan Dharma Giri tema keseluruhan menerapkan tema formal berupa garis lurus, hal tersebut dikarenakan desain yang digunakan pada setiap lokasi menggunakan tema yang sama yaitu tema formal atau penanaman tanaman dengan pola garis lurus. Untuk prinsip irama, dapat dilihat dengan adanya pengulangan tanaman tertentu atau repetisi disetiap bagian median jalan, dilihat dari tanaman pohon memiliki jarak titik tanam jarang sedangkan semak tinggi dan semak rendah memiliki jarak titik tanam rapat. Sedangkan pada prinsip keseimbangan dapat dilihat dengan adanya perbedaan tinggi rendah tanaman yang digunakan di median jalan, tanaman yang terdapat pada lansekap jalan Dharma Giri memiliki jarak titik tanam yang rapat hal ini dapat mendukung dalam memaksimalkan fungsi tanaman lansekap jalan sebagai pengarah dan penghalau cahaya kendaraan. 
Murdaningsih (2010) menyatakan bahwa tanaman lansekap pada jalan harus memenuhi efisiensi, keamanan dan kenyamanan serta penampilan yang menarik demi kelancaran sirkulasi pengguna jalan yang mana fungsi tanaman dapat dijadikan sebagai panduan dalam pemilihan tanaman, jenis tanaman yang di tanam pada lansekap jalan sebaiknya memiliki lebih dari satu fungsi selain sebagai penunjang aspek estetika namun bermanfaat juga dari aspek ekologi dan aspek arsitektural. Murdaningsih juga menambahkan, pemilihan jenis tanaman sebaiknya disesuaikan dengan fungsi yang akan dimunculkan sesuai dengan tempat dimana tanaman tersebut akan ditanam. Tanaman yang ditanam pada lansekap jalan umumnya berfungsi sebagai pembatas atau pemisah jalur yang berlawanan, pengaman dari benturan, sebagai pengarah pengguna jalan kearah tujuan tertentu, membantu mereduksi pencemaran udara, dapat sebagai pemecah angin, pencegah erosi, pengalihan parkir ilegal pada tepi jalan, dapat menjadi habitat bagi satwa dan sebagai penghalang sinar lampu kendaraan bermotor pada malam hari (Saputri,2017).

\section{Simpulan dan Saran \\ 4.1 Simpulan}

Secara umum kondisi lansekap jalan di Jalan Dharma Giri terdiri dari 20 jenis vegetasi yang pada lokasi penelitian yang meliputi pohon, semak, dan penutup tanah. Berdasarkan hasil skoring kesesuaian vegetasi tanaman yang tergolong sangat sesuai yaitu Nusa Indah, Kembang Kertas, Puring, Pangkas merah dan kuning, Bunga Taiwan Beauty, Bunga Sepatu, Melati Perancis, Jaburan, Ararea, Soka Mini, dan Pucuk Merah. Tanaman yang tergolong sesuai yaitu Kiara Payung, Bungur, Kamboja, Palem Raja, Euphorbia, Ruelia, Pisang Hias dan Rumput Jepang. Untuk penataan tanaman pada lansekap jalan telah memenuhi tiga prinsip perancangan (tema, irama, dan keseimbangan) namun penanaman tanaman seperti Bougenville dan Euphorbia perlu dihindari karena memiliki duri, serta terdapat Palem Raja pada median jalan yang pelepahnya yang kerap kali jatuh di badan jalan, Kembang Sepatu, Pisang Hias yang terlihat kering dan mati perlu pengawasan serta perawatan yang lebih intensif untuk memaksimalkan fungsinya sebagai lansekap jalan, dan juga Kiara Payung yang menyalahi regulasi karena tingginya melebihi kabel listrik. Sedangkan untuk kegiatan pemeliharaan tanaman perlu ditingkatkan agar lansekap jalan terjaga keindahan, kerapian serta fungsinya.

\subsection{Saran}

Penelitian ini dikhususkan untuk membahas mengenai kesesuaian beserta penataan tanaman pada lansekap jalan di Jalan Dharma Giri. Oleh karena itu perlu adanya penelitian lebih lanjut mengenai pemilihian keragaman vegetasi yang lebih variatif yang dapat meningkatkan pemaksimalan fungsi sebagai tanaman lansekap jalan sehingga semua elemen lansekap jalan pada Jalan Dharma Giri Gianyar dapat terpenuhi.

\section{Daftar Pustaka}

Agus, N.D.P. 2014. Evaluasi Pemilihan Jenis dan Penataan Tanaman pada Median Jalan Kota Malang. Jurnal Protan 3(4)

Budiyono, D. 2012. Lanskap Kota Malang Sebagai Obyek wisata Sejarah Kolonial. Jurnal Lanskap Indonesia. $4(1)$.

Direktorat Jenderal Bina Marga. 1996. Peraturan Lansekap Jalan Nomor 033/TBM/1996 Tentang Tata Cara Perencanaan Teknik Lansekap Jalan, Jakarta.

Murdaningsih, 2010. Evaluasi Aspek Fungsi, Estetika dan Agronomis Tanaman Tepi Jalandi Jalan Ijen Kota Malang. Jurnal Agrica. 1(1).

Lawalata, G.M. 2011. Perencanaan Lansekap Jalan Perkotaan. Kementrian Pekerjaan Umum. Bandung.

Peraturan Mentri Pekerjaan Umum. 2012. Nomor 05/PRT/M/2012 Tentang Pedoman Penanaman Pohon Pada Sistem Jaringan Jalan.

Saputri, A.W. 2017. Evaluasi Tata Hijau Lanskap Kampus Universitas Lampung. Skripsi. Tidak Dipublikasikan 